\title{
Real Interest Rate Persistence in South Africa: Evidence and Implications
}

\author{
Sonali Das * $\quad$ Rangan Gupta ${ }^{\dagger} \quad$ Patrick T. Kanda ${ }^{\ddagger}$ Monique Reid ${ }^{\S}$ \\ Christian K. Tipoy ${ }^{\mathbb{I}} \quad$ Mulatu F. Zerihun ${ }^{\prime}$
}

October 7, 2012

\begin{abstract}
The real interest rate is a very important variable in the transmission of monetary policy. It features in vast majority of financial and macroeconomic models. Though the theoretical importance of the real interest rate has generated a sizable literature that examines its long-run properties, surprisingly, there does not exist any study that delves into this issue for South Africa. Given this, using quarterly data (1960:Q2-2010:Q4) for South Africa, our paper endeavors to analyze the long-run properties of the ex post real rate (EPRR) by using tests of unit root, cointegration, fractional integration and structural breaks. In addition, we also analyze whether monetary shocks contribute to fluctuations in the real interest rate based on test of structural breaks of the rate of inflation as well as Bayesian change point analysis. Based on the tests conducted, we conclude that the South African EPPR can be best viewed as a very persistent but ultimately mean-reverting process. Also, the persistence in the real interest rate can be tentatively considered as a monetary phenomenon.
\end{abstract}

Keywords: Real Interest Rate, Monetary Policy, Persistence, Mean Reversion.

JEL Classification: C22, E21, E44, E52, E62, G12.

\section{Introduction}

Macroeconomic and financial theoretical models, e.g. the consumption-based asset pricing model (Lucas, 1978; Breeden, 1979; Hansen and Singleton, 1982, 1983), neoclassical growth models (Cass, 1965; Koopmans, 1965), central bank policy models (Taylor, 1993) and many monetary transmission mechanism models include the real interest rate (interest rate less expected or realized inflation rate) as a key variable. Hence, the viability of these models would depend upon the timeseries properties of the real interest rate. Further, the answer to the question as to whether financial markets fluctuate excessively is also determined by the movement of real interest rate (Shiller, 1979). Finally, the fact that the real interest rate is a crucial determinant of investment, savings and virtually all intertemporal decisions, makes an analysis dealing with the characteristics of the real interest rate highly pertinent. The behavior of the real interest rate thus tends to provide an implicit test of the different theoretical models. There are two types of real interest rates: the

\footnotetext{
${ }^{*}$ Logistics and Quantitative Methods, CSIR Built Environment, P.O. Box: 395, Pretoria, 0001, South Africa.

${ }^{\dagger}$ Corresponding author, Department of Economics, University of Pretoria, Pretoria 0002, South Africa, phone: +27 (012) 420 3460,Email: Rangan.Gupta@up.ac.za.

${ }^{\ddagger}$ Ph.D. Candidate Department of Economics, University of Pretoria, Pretoria 0002, South Africa.

$\S$ Department of Economics, University of Stellenbosch, Private Bag X1, 7602 Matieland, South Africa.

"Ph.D. Candidate Department of Economics, University of Pretoria, Pretoria 0002, South Africa.

"Ph.D. Candidate Department of Economics, University of Pretoria, Pretoria 0002, South Africa.
} 
ex ante real interest rate (EARR) and the ex post real rate (EPRR). Economic agents base their decisions on their expectations about the inflation level over the decision horizon. As such, the EARR turns out to be the appropriate gauge for assessing economic decisions. However, given that the EARR cannot be directly observable, we cannot evaluate its time-series properties.

Though the theoretical importance of the real interest rate has generated a sizable empirical literature $^{1}$ that examines its long-run properties, surprisingly, to the best of our knowledge, there does not exist any study that delves into this issue for South Africa. ${ }^{2}$ Against this backdrop, using quarterly data (1960:Q2-2010:Q4) for South Africa, our paper endeavors to analyze the long-run properties of the EPRR by using tests of unit root, cointegration, confidence intervals for the sum of the autoregressive coefficients, fractional integration and structural breaks. The time-series properties of the real interest rate would allow us to draw inferences regarding the viability of the theoretical models in the context of South Africa. Unit root and cointegration tests would help us investigate whether real interest rate is mean-reverting in South Africa. However, given that unit root and cointegration tests suffer from low power if the true model is a highly persistent but stationary process, we directly analyze the persistence property of the real interest rate using fractional integration and estimating confidence intervals for the sum of the autoregressive coefficients. Note that, from a policy perspective as well, there is a tremendous need to determine whether the process of real interest rate is stationary or not. Given that the central bank implements monetary policy by controlling the real interest rate, then changes in the real rate, when the real rate is nonstationary, implies that the policy will have a permanent and not a transitory effect. Thus, if the central bank wants a temporary effect, it will have to intervene in the future to offset its initial effect. On the other hand, if the real interest rate is stationary, then a monetary policy change in the real interest rate rate will eventually return to its "equilibrium" level without further intervention by the central bank. Clearly then, there are implications, especially in terms of monetary policy intervention and proper functionality of the markets, depending on the knowledge about the mean-reversion and persistence properties of the real interest rate. Hence, the exact knowledge of the property of real interest rate is always important, but it is moreso now for South Africa, given that it has moved to an inflation-targeting regime since the first quarter of $2000 .{ }^{3}$ The success of an inflation-targeting regime is dependant on keeping the inflation expectations pegged, which in turn, depends on clear communication to the market, and hinges crucially to a great extent on whether the real interest rate is stationary or not. Since if the real interest rate is believed to have an unit root process, the South African Reserve Bank might have to intervene regularly to neutralize the possibility of a permanent effect on the market; in the process confusing agents and their inflation expectations, and thus leading the inflation to deviate away from the target.

In addition to analyzing the mean-reverting and persistence properties of the real interest rate, we also analyze whether monetary shocks contribute to fluctuations in the real interest rate based on the Bai and Perron (1998) test of structural breaks of the rate of inflation, as well as, Bayesian change point analysis proposed by Barry and Hartigan (1993) - a methodology, though widelyused in the statistical literature to analyze change-points, ${ }^{4}$ has never been used in the literature pertaining to the sources behind the fluctuations of the real interest rate. So our study contributes to the the literature on the time-series properties of the real interest rate by being the first to provide a case-study for South Africa, and also, the being first study to use the novel approach of

\footnotetext{
${ }^{1}$ See Neely and Rapach (2008) for a detailed literature review.

${ }^{2}$ Studies that exists for South Africa only deals with the uncovered interest rate parity condition, or in other words, the interest rate behavior of South Africa relative to other developed or emerging economies. See for example Kahn and Farrell (2002), Kryshko (2006), Lacerda et al., (2010) and de Bruyn et al., (forthcoming).

${ }^{3}$ In February of 2000, the Minister of Finance announced that inflation targeting would be the sole objective of the South African Reserve Bank. Currently, the Reserve Bank's main monetary policy objective is to maintain CPI inflation between a target-band of three to six percent, using discretionary changes in the repo rate as its main policy instrument.

${ }^{4}$ See Erdman and Emerson (2007) for a detailed literature review in this regard.
} 
Bayesian change point analysis in looking for a reason behind that explains the variation in the real interest rate. Our main results can be summarized as follows: Though, the unit root tests reveal that the real interst rate is stationary, cointegration analysis tends to suggest otherwise. Realizing that unit root and cointegration tests suffer from low power if the true model is a highly persistent but stationary process, we directly analyzed the persistence property of the real interest rate. Fractional integration and estimation of the confidence intervals for the sum of the autoregressive coefficients, suggested that the unit real interest rate is a persistent process. So, in general, these results on persistence, coupled with the unit root tests led us to conclude that the real interest rate in South Africa is a persistent but mean-reverting process. Further, we observed that, real interest is far more persistent than the consumption growth rate, thus raising doubts about the validity of the consumption-based asset pricing models. Complex equilibrium growth models tend to potentially explain this persistence mismatch through changing fiscal and monetary policy, as well as temporary technology growth shocks. Given this we considered fiscal, monetary, and transient technology shocks as potential causes of persistent fluctuations in the South African real interest rate. Our results based on test of structural breaks of the rate of inflation, and in particular, Bayesian change point analysis, tentatively concludes that real interest rate persistence is more likely to be a monetary phenomenon than a outcome of fiscal policy and transient technology growth shocks. In other words, the mismatch between the persistence properties of consumption growth and the real interest rate is possibly due to monetary policy shocks. The remainder of the paper is organized as follows: Section 2 discusses the theoretical background on the long-run behavior of the real interest rate. Section 3 lays out the difference between the EARR and EPRR and presents the results from the unit root, cointegration and fractional integration tests while Section 4 analyzes structural breaks in the real interest rate. Section 5 investigates the monetary explanation of persistence, and finally Section 6 concludes the paper.

\section{Theoretical Background}

\section{Consumption-Based Asset Pricing Model}

Lucas (1978), Breeden (1979), and Hansen and Singleton (1982, 1983)'s canonical consumption based asset pricing model hypothesizes a representative household choosing a real consumption sequence, $\left\{c_{t}\right\}_{t=0}^{\infty}$, to solve the problem:

$$
\max \sum_{t=0}^{\infty} \beta^{t} u\left(c_{t}\right),
$$

subject to an intertemporal budget constraint. $\beta$ is a discount factor and $u\left(c_{t}\right)$ represents an instantaneous utility function. The first-order condition yields the intertemporal Euler equation,

$$
E_{t}\left\{\beta\left[u^{\prime}\left(c_{t+1}\right) / u^{\prime}\left(c_{t}\right)\right]\left(1+r_{t}\right)\right\}=1,
$$

where $1+r_{t}$ represents the gross one-period real interest rate with payoff at period $t+1$ and $E_{t}$ is the conditional expectation operator. Many studies often consider the utility function to have the constant relative risk aversion (CRRA) form, $u\left(c_{t}\right)=c_{t}^{1-\gamma} /(1-\gamma)$, where $\gamma$ is the coefficient of relative risk aversion. Combining the CRRA form of the utility function with the assumption of joint log-normality of consumption growth and the real interest rate, the log-linear version of equation (1) can be written as (Hansen and Singleton, 1982, 1983):

$$
\kappa-\gamma E_{t}\left[\Delta \log \left(c_{t+1}\right)\right]+E_{t}\left[\log \left(1+r_{t}\right)\right]=0,
$$


where $\Delta \log \left(c_{t+1}\right)=\log \left(c_{t+1}\right)-\log \left(c_{t}\right)=\log (\beta)+0.5 \sigma^{2}$, and $\sigma^{2}$ is the constant conditional variance of $\log \left[\beta\left(c_{l+1} / c_{l}\right)^{-\alpha}\left(1+r_{l}\right)\right]$. Equation (2) relates the conditional expectations of the per capita real consumption growth rate $\left[\Delta \log \left(c_{t+1}\right)\right]$ with the (net) real interest rate $\left[\log \left(1+r_{t}\right) \approx r_{t}\right]$. According to Rose (1988), if equation (2) is to hold, then the per capita real consumption growth rate and the (net) real interest rate series must have the same integration properties. Bearing in mind that $\left[\Delta \log \left(c_{t+1}\right)\right]$ is nearly without doubt a stationary process, Rose (1988) shows that the real interest rate is non-stationary i.e. $r_{t} \sim I(1)$ in many industrialized countries. A unit root in the real interest rate together with stationary consumption growth imply that permanent changes in the level of the real rate will be unmatched by such changes in consumption growth. Therefore, equation (2) seemingly cannot hold. The problem identified by Rose (1988) is vindicated in Figure 1, which plots South Africa's ex-post 3-month Treasury bill based real interest rate and annualized per capita consumption growth rate for the period from 1960:Q2 to 2010:Q4. Figure 1 shows that the two series seem to be divergent for most of the period prior to the 1980s whereas the series appear to track each other quite well during the early 1980s and from the late 1980s to the last date of the sample.

Fig. 1: Ex Post Real Interest Rate and Real per capita Consumption Growth, 1960:Q22010:Q4

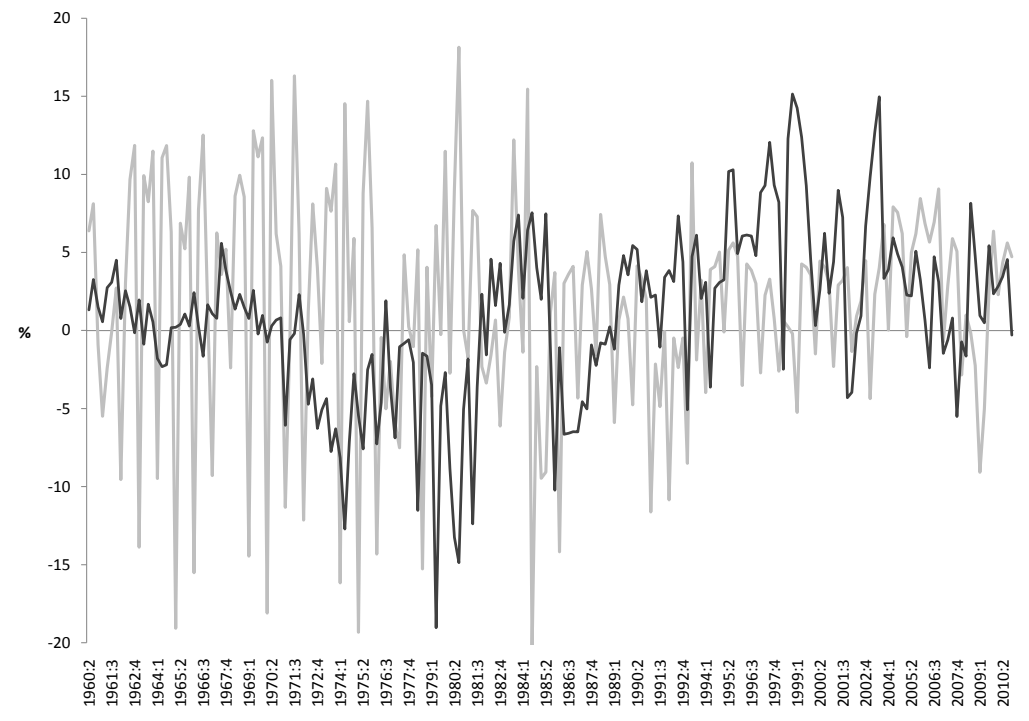

—Per Capita Consumption Growth — Ex Post Real Interest Rate

NOTE: The figure plots SA ex post 3-month real interest rate and annualized per capita consumption growth. Consumption includes nondurable goods and services consumption.

The most elementary consumption-based asset pricing model is based on an endowment economy with a representative household and constant preferences. However, more elaborate theoretical models allowing for changes in fiscal or monetary policy to affect the steady-state real interest rate, while leaving the steady-state consumption growth rate unaffected have been proposed in the literature. These models allow a disparity in the integration properties of the consumption growth and real interest rates. These models are summarized in the next subsections.

\section{Equilibrium Growth Models and the Steady-State Real Interest Rate}

Euler equations such as equations (1) and (2) and suggesting sources of a unit root in real interest rates emanate from general equilibrium growth models with a production technology. In particular, the neoclassical growth model by Cass (1965) and Koopmans (1965), featuring a representative 
profit-maximizing firm and utility-maximising household, hypothesizes that the steady state real interest rate is a function of time preference, risk aversion, and the steady-state growth rate of technological change (Blanchard and Fischer, 1989, Chap. 2; Barro and Sala-i-Martin, 2003, Chap.3; Romer, 2006, Chap.2; Neely and Rapach, 2008). The assumption of constant relative risk aversion utility in the neoclassical growth model by Cass (1965) and Koopmans (1965) implies the steady-state condition:

$$
r^{*}=\zeta+\gamma z
$$

where $r^{*}$ is the steady-state real interest rate, $\zeta=-\log (\beta)$ is the rate of time preference, and $\mathrm{z}$ represents the (expected) steady-state growth rate of labor augmenting technological change. Equation (3) suggests that the steady state real interest rate is affected by a permanent change in the exogenous rate of time preference, risk aversion, or long-run growth rate ${ }^{5}$. The steady-state version of equation (2) is given by:

$$
-\zeta-\gamma[\Delta \log (c)]^{*}+r^{*}=0,
$$

where $[\Delta \log (c)]^{*}$ is the steady-state growth rate of $c_{t}$. Substituting the right-hand side of equation (3) into equation (4) for $r^{*}$, we get the expression $[\Delta \log (c)]^{*}=z$ i.e. steady-state consumption growth is a function of the steady-state technology growth.

A change in the rate of time preference $(\zeta)$, risk aversion $(\gamma)$, and/or steady-state rate of technology growth $(z)$ will require corresponding changes in the steady-state real interest rate as defined in equation (3). The size and frequency of such changes determine whether real interest rates is very persistent and exhibit unit root behavior and/or structural breaks. Only a change in the steady-state growth rate of technology can alter both the real interest rate and consumption growth, generating non-stationary behavior in both variables. Therefore, it cannot explain the difference in the integration properties of the real interest rate and consumption growth as identified by Rose (1988).

On the other hand, shocks to the preference parameters $(\zeta)$ and $(\gamma)$ will only affect the steady state real interest rate and not steady-state consumption growth. Thus, changes in preferences represent a potential disconnecting factor between the integration properties of real interest rates and consumption growth. Studies generally consider preferences to be stable, however, making it difficult to attribute the persistence mismatch to such changes.

Other factors e.g. permanent changes in government purchases and their financing can change the steady-state real interest rate without affecting steady-state consumption growth in more complex models such as overlapping-generations models with heterogeneous households (Samuelson, 1958; Diamond, 1965; Blanchard, 1985; Blanchard and Fischer, 1989, Chap. 3; Romer, 2006, Chap. 2). Therefore, these models potentially explain the disparity in the integration properties of the real interest rate and consumption growth as observed in Rose (1988).

Lastly, some monetary growth models (Mundell, 1963; Tobin, 1965; Weiss, 1980; Espinosa-Vega and Russell, 1998a,b; Bullard and Russell, 2004;Reis, 2007; Lioui and Poncet, 2008) permit for changes in steady-state money growth to alter the steady-state real interest rate without matching changes in consumption growth, potentially justifying a disparity in the integration properties of the real interest rate and consumption growth. Mundell (1963) and Tobin (1965) hypothesize that an increase in steady-state money growth decreases the steady-state real interest rate. Other recent microfounded monetary models (Weiss, 1980; Espinosa-Vega and Russell, 1998a,b; Bullard and Russell, 2004;Reis, 2007; Lioui and Poncet, 2008) have corroborated the findings of Mundell (1963) and Tobin (1965).

\footnotetext{
${ }^{5}$ The steady state real interest rate could also be affected by changes in distortionary tax rates (See Blanchard and Fischer, 1989, pp 56-59).
} 


\section{Transitional Dynamics}

The previous subsection discussed factors that affects the steady-state real interest rate. There are, however, other shocks that can have persistent, but transitory, effects on the real interest rate. To illustrate, a temporary increase in government purchases or technology growth in the neoclassical growth model results in a constantly (but not permanently) higher real interest rate (Romer, 2006, Chap. 2). Furthermore, monetary shocks can persistently alter the real interest rate through different types of frictions e.g. "sticky" prices and information, adjustment costs, and learning by agents about policy regimes. Transient technology and fiscal shocks, as well as monetary shocks, can also explain differences in the persistence of real interest rates and consumption growth. For instance, based on a calibrated neoclassical equilibrium growth model, Baxter and King (1993) argue that a fiscal shock in the form of a four-year increase in government purchases persistently increases the real interest rate. However, the effect is temporary as the real interest rate eventually returns to its initial level. On the other hand, the fiscal shock generates a much less persistent effect on consumption growth. So, the evidence of highly persistent but mean-reverting behavior, if obtained in real interest rates, could provide support to the empirical relevance of these shocks for South Africa.

\section{Testing the Integration Properties of Real Interest Rates}

\section{Ex Ante versus Ex Post Real Interest Rates}

The ex ante real interest rate (EARR) refers to the nominal interest rate less the expected inflation rate. On the other hand, the ex post real rate (EPRR) refers to the nominal interest rate less actual inflation. Economic agents base their decisions on their expectations about the inflation level over the decision horizon. To illustrate, the Euler equations (1) and (2) link the expected marginal utility of consumption to the expected real return. Consequently, the EARR turns out to be the appropriate gauge for assessing economic decisions. However, given that expected inflation is not directly observable, the EARR cannot be directly observable as well. Hence, implying that we cannot evaluate its time-series properties. One immediate solution is to use some measure of inflation expectations based on a survey. However, economists often are not ready to accept survey forecasts as measure of expectations, citing doubts over the quality of the surveys conducted (Mishkin, 1981). Further, obtaining survey based inflation expectations measure at the desired frequency is also an obstacle (Neely and Rapach, 2008).

Two alternative approaches to the problem of unobserved expectations exists. The first approach uses econometric forecasting methods to construct inflation forecasts (Mishkin, 1981, 1984; Huizinga and Mishkin,1986). However, all the appropriate information used by economic agents when forming their inflation expectations might not included in econometric forecasting methods, and hence, these forecasting models fail to change with the structure of the economy.

The second approach uses the actual inflation rate as a proxy for inflation expectations. By definition, the actual inflation rate at time $t\left(\pi_{t}\right)$ is the sum of the expected inflation rate and a forecast error term $\left(\varepsilon_{t}\right)$ :

$$
\pi_{t}=E_{t-1} \pi_{t}+\varepsilon_{t} .
$$

If expectations are formed rationally, as argued by the literature on real interest rates, $E_{t-1} \pi_{t}$ should be an optimal forecast of inflation (Nelson and Schwert, 1977), and $\varepsilon t$ should therefore be a white noise process. The EARR can then be approximately expressed as:

$$
r_{t}^{e a}=i_{t}-E_{t} \pi_{t+1}
$$


where $i_{t}$ is the nominal interest rate. Solving equation (3) for $E_{t}\left(\pi_{t+1}\right)$ and substituting it into equation (4), we obtain

$$
\begin{aligned}
r_{t}^{e a} & =i_{t}-\left(\pi_{t+1}-\varepsilon_{t+1}\right) \\
& =i_{t}-\pi_{t+1}+\varepsilon_{t+1}=r_{t}^{e p}+\varepsilon_{t+1},
\end{aligned}
$$

where $r_{t}^{e p}=i_{t}-\pi_{t+1}$ is the EPRR. Equation (5) implies that, under rational expectations, only a white noise component distinguishes the EPRR from the EARR. Consequently, the EPRR and EARR will have the same long-run (integration) properties. Note that, this result holds if the expectation errors $\left(\varepsilon_{t+1}\right)$ are stationary, and does not necessarily requires expectations to be formed rationally (Peláez, 1995; Andolfatto et al., 2008). Following the work of Rose (1988), by assuming that inflation-expectation errors are stationary, the empirical literature, in general, tests the integration properties of the EARR with the EPRR.

The literature usually assesses the integration properties of the EPRR through a decision rule. First, the individual components of the EPRR i.e. $i_{t}$ and $\pi_{t+1}$ are analyzed. If unit root tests reveal that both $i_{t}$ and $\pi_{t+1}$ are $I(0)$, then EPRR is stationary. On the other hand, if $i_{t}$ and $\pi_{t+1}$ have different orders of integration e.g. $i_{t} \sim I(1)$ and $\pi_{t+1} \sim I(0)$, then EPRR must be non-stationary, as a linear combination of an $I(0)$ process and an $I(1)$ process results in an $I(1)$ process. Lastly, if both $i_{t}$ and $\pi_{t+1}$ are $I(1)$, then stationarity of the EPRR is assessed through a cointegration test of $i_{t}$ and $\pi_{t+1}$ i.e. testing if the linear combination $i_{t}-\left[\theta_{0}+\theta_{1} \pi_{t+1}\right]$ is stationary. Two approaches are used in the literature: First, a cointegrating vector of $\left(1,-\theta_{1}\right)^{\prime}=(1,-1)^{\prime}$ is imposed and thereafter a a unit root test of $r_{t}^{e p}=i_{t}-\pi_{t+1}$ is applied. Such an approach usually has more power to reject the null of cointegration when the true cointegrating vector is $(1,-1)^{\prime}$. Alternatively, the second approach involves freely estimating the cointegrating vector between $i_{t}$ and $\pi_{t+1}$ thereby allowing for tax effects (Darby, 1975). If $i_{t}$ and $\pi_{t+1}$ are $I(1)$ processes then EPRR requires $\theta_{1}=1$ or $\frac{1}{1-\tau}$ with $\tau$ being the marginal tax rate on the nominal interest income. Generally, estimates of $\theta_{1}$ in the range of 1.30 to 1.40 is considered plausible when allowing for tax effects, since this would imply a marginal tax rate of 20 to 30 percent (see Crowder and Wohar (1999) for an empirical exposition in this regard.). Note that cointegration between $i_{t}$ and $\pi_{t+1}$ does not necessarily imply that the EPRR is stationary, one requires $\theta_{1}=1$ or $\frac{1}{\tau}$ in addition, since other values of $\theta_{1}$ would imply that the equilibrium real interest rate varies with inflation. ${ }^{6}$

\section{Unit Root and Cointegration Tests}

There exist a vast literature on unit root and cointegration tests applied to assessing the time series properties of the real interest rate. ${ }^{7}$ Table 1 illustrates the unit root tests based on the augmented Dickey and Fuller (1979) [ADF], the Dickey and Fuller test with Generalized Least Squares detrending (DFGLS) developed by Elliot, Rothenberg, and Stock (1996), and the $M Z_{\alpha}$ test proposed by Ng and Perron (2001) for the South African 3-month Treasury bill rate, the Consumer Price Index (CPI) inflation, the ex post real interest rate and the per capita consumption growth rate. The $M Z_{\alpha}$ statistic is designed to have better size and power properties than the ADF test. Note that the data for the Treasury bill rate and CPI are obtained from International Monetary Fund's International Financial statistics (IFS), while, the data on consumption is obtained from the Quarterly Bulletins of the South African Reserve Bank, and are converted to per capita form using popula-

\footnotetext{
${ }^{6}$ Although much of the empirical literature analyzes EPRR in this manner, the time-series properties of EPRR can differ from those of the EARR, mainly because of two reasons: First, at short-horizons, the behavior of EPRR could differ from that of the EARR, and; second, some estimation techniques can generate different persistence properties between the EARR and EPRR. The reader is referred to Neely and Rapach (2008) for further details.

${ }^{7}$ This can be found in Neely and Rapach (2008).
} 
tion figures obtained from the World Bank's World Development Indicators (WDI). ${ }^{8}$ The raw data covers the quarterly period of 1960:Q1-2010:Q4, which post transformations yields a data set that starts in 1960:Q2.9

Consistent with the literature, none of the tests rejects the null hypothesis of unit root for the nominal interest rate, when we look at the critical values at the 5 percent level. Note that, the $M Z_{\alpha}$ statistic fails to reject the null of unit root at the 10 percent level of significance for the nominal Treasury bill rate. ${ }^{10}$ For the inflation rate though, evidence against stationarity is exceptionally strong. The failure of the $M Z_{\alpha}$ statistic to reject the null of unit root for either inflation and the nominal interest rate at the conventional (5 percent) level of significance argues for cointegration analysis of these two variables to determine the EPRR's integration properties. When we prespecify a $(1,-1)^{\prime}$ cointegrating vector and apply unit root tests to the EPRR, we reject the null at the 1 percent level of significance for the DFGLS, 5 percent level of significance for the $M Z_{\alpha}$ statistic and at the 10 percent level for the ADF statistic. Thus, the EPRR appears to be stationary for South Africa.

Table 1: Unit Root Test Statistics, 1960:Q2-2010:Q4

\begin{tabular}{llll}
\hline \hline Variable & ADF & DFGLS & $M Z_{\alpha}$ \\
\hline 3-Month Treasury Bill Rate & $-2.48[1]$ & $-1.38[7]$ & $-7.00^{*}[1]$ \\
Inflation Rate & $-1.80[7]$ & $-1.45[6]$ & $-2.51[7]$ \\
Ex Post Real Interest Rate & $-2.60 *[8]$ & $-6.19 * * *[0]$ & $-10.27 * *[7]$ \\
Per Capita Consumption Growth & $-4.14 * * *[7]$ & $-12.43 * * *[0]$ & $-9.24 * *[8]$ \\
\hline \hline
\end{tabular}

NOTE: The ADF and $M Z_{\alpha}$ statistics correspond to a one-sided (lower-tail) test of the null hypothesis that the variable has a unit root against the alternative hypothesis that the variable is stationary. $-2.58,-2.89$ and -3.51 are the 10 percent, 5 percent and 1 percent critical values respectively for the ADF statistic and, $-2.58,-2.89$ and -3.51 are the 10 percent, 5 percent and 1 percent critical values respectively for the DFGLS statistic $-1.62,-1.94$ and -2.58 , while, $-5.70,-8.10$ and -13.80 are the 10 percent, 5 percent and 1 percent critical values for the $M Z_{\alpha}$ statistic respectively. The lag order for the regression model used to compute the test statistic is reported in brackets and is chosen by the Modified AIC based on a mximum lag of 14. **** and *** indicate significance at the 10 percent, 5 percent and 1 percent levels.

To test the null hypothesis of no cointegration without pre-specifying a cointegrating vector, Table 2 reports the single-equation augmented Engle and Granger (1987) [AEG] and $M Z_{\alpha}$ statistic from Perron and Rodriguez (2001), and trace statistic from Johansen (1991). All these statistics fail to reject the null hypothesis that the Treasury bill rate and inflation are not cointegrated. ${ }^{11}$ Though the evidence on stationarity of the EPRR is mixed depending on whether we use unit root or coin-

\footnotetext{
${ }^{8}$ The annual population figures are interpolated to quarterly values.

${ }^{9}$ Specifically as far as the data is concerned, the 3-month Treasury constant maturity rate monthly data are converted to quarterly frequency by averaging over the three months comprising a quarter. The annualized CPI inflation rate is based on the seasonally adjusted (at an annual rate) CPI with the base year of 2005. Ex post real interest rate is defined as the three-month Treasury bill rate minus the realized inflation rate in the subsequent quarter. Finally, the annualized consumption growth rate is based on real personal consumption expenditures (base year of 2005) adjusted seasonally at an annual rate. Annualized inflation and consumption growth rates are computed by taking 400 times the first differences of the natural logs of the CPI deflator and consumption.

${ }^{10}$ Given this, we also conducted the Phillips and Perron (1988) [PP], Elliot, Rothenberg, and Stock (1996) [ERS] point-optimal test and the Kwiatkowski et al., (1992) [KPSS] unit root tests on the treasury bill rate. The PP test could not reject the null of unit root even at the 10 percent level, while the KPSS test rejected the null of stationarity at one percent level of significance. However, the ERS point-optimal test rejected the null of unit root even at 1 percent level. In addition, we also tested the EPRR based on the PP, ERS point-optimal test and KPSS test. The null of unit root was rejected even at one percent based on the PP test, while the null of stationarity could not be rejected at 5 percent based on the KPSS, but the ERS could not reject the null of unit root at even 10 percent. Further, nonlinear unit root test proposed by Kapetanios et al., (2003) [KSS] and the Bayesian unit root test developed by Sims (1988) was also used. Both the KSS and the Bayesian tests rejected the null of unit root. These results are available upon request from the authors.

${ }^{11}$ Following Gregory and Hansen (1996), we also tested for cointegration using residual based tests that allows for regime shifts, but the null of no cointegration could not be rejected even at 10 percent level of significance. Similar
} 
tegration tests, ${ }^{12}$ per capita consumption growth is clearly stationary based on the ADF, DFGLS and $M Z_{\alpha}$ statistics, thus highlighting the difference that may exist in the persistence properties of these two variables. As unit root and cointegration tests have low power to reject the null if the true model is a highly persistent but stationary process (Dejong et al., 1992), the next step will be to analyze the specifically the persistence property of the EPRR.

Table 2: Cointegration Test Statistics, 3-Month Treasury Bill Rate and Inflation Rate (1960:Q2-2010:Q4)

\begin{tabular}{lll}
\hline \hline Cointegration tests & & \\
\hline AEG & $M Z_{\alpha}$ & Trace \\
$-2.39[7]$ & $-10.46[3]$ & $13.53[4]$ \\
\hline \hline
\end{tabular}

NOTE: The AEG and $M Z_{\alpha}$ statistics correspond to a one-sided lower tail test of the null hypothesis that the 3-month T-bill and inflation rate are not cointegrated against the alternative hypothesis that the variables are cointegrated. The $10 \%, 5 \%$ and $1 \%$ critical values for the AEG statistic are $-3.14,-3.37$ and-3.95. The $10 \%, 5 \%$ and $1 \%$ critical values for the $M Z_{\alpha}$ are $-12.80,-15.84$ and -22.84 . The trace statistic corresponds to a one-sided upper-tail test of the null hypothesis that the 3-month treasury bill rate and inflation are not cointegrated against the alternative that the variables are cointegrated. The $10 \%, 5 \%$ and $1 \%$ critical values for the trace statistic are 17.77, 20.87 and 27.70. The lag order for the regression model used to compute the test statistic is reported in bracket.

\section{Confidence Intervals for the Sum of the Autoregressive Coefficients}

The sum of the AR coefficients, $\rho$, in the AR representation of $i_{t}-\pi_{t+1}$ equals unity for an $I(1)$ process, while $\rho<1$ for an $I(0)$ process. However, it is inherently difficult to differentiate an $I(1)$ process from a highly persistent $I(0)$ process, as the two types of processes can be observationally equivalent (Blough, 1992; Faust, 1996). We need to determine a range of values for $\rho$ that are consistent with the data to analyze the theoretical implications of the time-series properties of the real interest rate, over and above whether $\rho$ is $\leq 1$. That is, a series with a $\rho$ value of 0.95 is highly persistent even if it does not contain a unit root as such, and it is much more persistent than a series with a $\rho$ value of 0.4 for example (Neely and Rapach, 2008).

Following the work of Rapach and Wohar (2004), the Hansen (1999) grid bootstrap and the Romano and Wolf (2001) sub-sampling procedures were used to compute a 95 percent confidence interval for $\rho$ in the $i_{t}-\pi_{t+1}$ process. The grid bootstrap for the EPRR is $(0.70,0.95)$ while the sub-sampling is $(0.68,0.92)$. The upper bounds are consistent with a highly persistent process. The grid bootstrap and sub-sampling intervals for per capita consumption growth are (-0.63, $0.09)$ and $(-1.18,0.45)$. The discrepancy between the upper bounds of the $\rho$ for per capita growth

conclusions were also reached based on both the Bierens (1997) and Breitung (2002) nonparametric cointegration tests, as these tests too failed to reject the null of no cointegration. Note that both these tests allow for nonlinearity of an unknown form in the short-run dynamics of the the two variables. Interestingly, even though no cointegration could be detected, estimates of $\theta_{1}$ based on the dynamic ordinary least squares (DOLS) or the Johansen (1991) methods are not significantly different from unity. However, this result, perhaps, explains as to why we detect stationarity for the EPRR based on the unit root tests with a prespecified cointegrating vector of $(1,-1)^{\prime}$. Further, using the nonparametric nonlinear co-trending analysis developed by Bierens (2000), the null hypothesis that there exists one co-trending vector between the nominal Treasury bill and the inflation rate could not be rejected. These results are available upon request from the authors.

${ }^{12}$ Until recently, researchers used models of cointegration that assumed both the cointegrating relationship and shortrun dynamics to be linear. But now studies have started to relax these linearity assumptions based on nonlinear cointegration or threshold dynamics, which in turn, allow the cointegrating relationship and mean reversion to be contingent on the current values of the variables. Given this, when we tested for nonlinear cointegration between the 3-month Treasury bill rate and the the inflation rate based on the test proposed by $\mathrm{Li}$ and Lee (2010), the null of no cointegration could not be rejected even at the 10 percent level of significance. This result is available upon request from the authors. It must be pointed out that, although evidence of threshold behavior could be interesting, these models do not obviate the persistence in the EPRR, since there are still regimes where the real interest rate behaves like an unit root process. 
rate of consumption and those of the lower bounds of the $\rho$ for the EPRR confirm the difference in persistence properties between the two variables again.

\section{Testing for Fractional Integration}

Unit root and cointegration tests determine whether a process is stationary or non-stationary (i.e., $I(0)$ or $I(1)$ ). The distinction between $I(0)$ and $I(1)$ implicitly restricts the types of allowed dynamic processes. As a result, studies such as Granger (1980), Granger and Joyeux (1980) and Hosking (1981) test for fractional integration in the EARR and EPRR. A fractionally integrated series is denoted by $I(d), 0 \leq d \leq 1$. If $d=0$, then the series is $I(0)$ and shocks decay at a geometric rate. If $d=1$, then the series is $I(1)$, and shocks have permanent effects. If $0<d<1$ then the series is mean-reverting as in the $I(0)$ case. However, shocks vanish at a much slower hyperbolic rate. Such series can be considerably more persistent than a very persistent $I(0)$ series (Neely and Rapach, 2008).

Testing for fractional integration in this paper is carried out by estimating the $d$ parameter using the Shimotsu (2008) semi-parametric two-step feasible exact local Whittle estimator, which allows for an unknown mean in the series. The estimate of $d$ for the South African EPRR is found to be 0.69 with a 95 percent confidence interval of $(0.49,0.89)$, suggesting long-memory, but meanreverting behavior. So we can reject the hypothesis that $d=0$ or $d=1 .^{13}$ The estimate of $d$ for per capita consumption growth is equal to 0.18 , with a 95 percent confidence interval of $(-0.02$, 0.38 ), suggesting that we cannot reject the null hypothesis of $d=0$ at conventional significance levels. ${ }^{14}$ The fractional integration results further corroborate the difference in persistence between the EPRR and per capita consumption growth.

\section{Testing for Regime Switching and Structural Breaks in Real Inter- est Rate}

Some studies test for structural breaks in real interest rate following Huizinga and Mishkin (1986). Taking into account the possibility for structural breaks can significantly lower the persistence within the identified regimes (Perron, 1989). Also, Jouini and Nouira (2006) argue that ignoring the possibility of the presence of structural breaks can generate spurious evidence of fractional integration (Neely and Rapach, 2008). Researchers, in general, have relied on Hamilton's (1989) Markov-switching approach to test for regime switching in the EPRR, whereby the model is assumed to be ergodic, implying that the current state will eventually cycle back to any possible state. Just as these models, structural breaks too have similar properties without being ergodic, suggesting that they do not necessarily tend to revert to previous conditions. Given that the literature on real interest rate tend to show no obvious tendency to return to previous state, structural breaks are considered to be more appropriate for modeling the EPRR than Markov-switching (Neely and Rapach, 2008).

We test for structural breaks in the unconditional mean of the EPRR using use the powerful

\footnotetext{
${ }^{13}$ Similar results were obtained for the fractional integration parameter of EPRR using the Geweke and Porter-Hudak (1983) and the Robinson (1992) methods, though the latter estimation strategy produced a relatively lower value of $d$. In addition, when we used the modified R/S statistic developed by Lo (1991), we confirmed the EPRR to be a long-memory process. These results are available upon request from the authors.

${ }^{14}$ This short-memory behavior of the per capita consumption growth rate was also confirmed by the Geweke and Porter-Hudak (1983) and the Robinson (1992) estimation of $d$, as well as by the modified R/S statistic which failed to reject the null hypothesis of the per capita consumption growth being a short-memory process. These results are available upon request from the authors.
} 
Table 3: Bai and Perron (1988) Test Statistics and Estimation Results for ex post Real Interest Rate (1960:Q2-2010:Q4)

\begin{tabular}{llcc}
\hline \hline Test statistic & \multicolumn{1}{c}{ Regime } & $\begin{array}{c}\text { Estimated ex post } \\
\text { real interest rate mean }\end{array}$ \\
\hline$U D_{\max }$ & $32.08^{* * *}$ & $1960: \mathrm{Q} 2-1989: \mathrm{Q} 1[1985: \mathrm{Q} 2-1994: \mathrm{Q} 1]$ & $-1.47^{* * *}(0.43)$ \\
$W D_{\max }(5 \%)$ & $38.13^{* *}$ & $1989: \mathrm{Q} 2-2010: \mathrm{Q} 4$ & $4.15^{* * *}(0.49)$ \\
$F(1 \mid 0)$ & $22.57^{* * *}$ & & \\
$F(2 \mid 1)$ & $10.45^{* *}$ & & \\
$F(3 \mid 2)$ & 4.86 & & \\
$F(4 \mid 3)$ & 4.39 & & \\
$F(5 \mid 4)$ & 0 & & \\
\hline \hline
\end{tabular}

NOTE: *,**,*** indicate significance at the $10 \%, 5 \%, 1 \%$ levels. The bracketed dates in the Regime column denote a $90 \%$ confidence interval for the end of the regime. Numbers in parentheses in the last column denote standard errors for the estimated mean.

methodology of Bai and Perron (1998) for testing for multiple structural breaks in a regression model. The results for the EPRR are reported in table 3. The procedure based on the sequential estimation finds one change in the mean of EPRR that has occurred in 1989:Q1. ${ }^{15}$ This break is associated with a significant change in the average annualized real interest rate in the two regimes. For the period between 1960:Q2 and 1989:Q1, the average real interest rate is at -1.47 percent, and then increases significantly at 4.15 percent for the period between 1989:Q2 and 2010:Q4. ${ }^{16}$ The finding of a significant break implies only a reduction in within-regime (local) persistence, but high degree of global persistence for the EPRR still remains. ${ }^{17}$. Figure 2 plots the South African EPRR and the means for the regimes defined by the structural break estimated using the Bai and Perron (1998) methodology.

\section{Is the Persistence of EPRR a Monetary Phenomenon?}

Based on the tests conducted above, we can conclude that the South African EPPR can be best viewed as a very persistent but ultimately mean-reverting process. This section considers what types of shocks are most likely to produce the persistence in the South African real interest rate. Let us recall the underlying motivation for learning about real interest rate persistence: In a simple endowment economy, the real interest rate should have the same persistence properties as consumption growth. However, our empirical analyses reveal that the real rate is much more persistent than consumption growth. Given that, permanent technology growth shocks can create a non-stationary real rate, but also affects consumption growth in the same way, they cannot account

\footnotetext{
${ }^{15}$ Note that in Table 3, we see that $F(2 \mid 1)$ is rejected meaning that we reject 1 break in favor of 2 breaks. Also, $F(3 \mid 2)$ is not significant, implying that we cannot reject 2 breaks in favor of 3 breaks. These results suggest 2 breaks. However, the 10 percent confidence interval around the endpoint of the first break, identified at 1974:1, so was so wide that it included the starting point of the sample. In light of this, we decided to choose one break rather than 2 for the EPRR. Further, if we allowed for two breaks, suggesting three regimes, the estimate of the mean EPRR (0.89) under the first regime was insignificant with a $t$-statistic of 1.42 . The details of these results are available upon request from the authors.

${ }^{16}$ In contrast to this evidence of a unique break in the EPRR, the Bai and Perron (1998) methodology obtained no structural break in the mean of per capita consumption growth. These results are available upon request from the authors.

${ }^{17}$ Note that, when we conducted the Zivot and Andrews (1992) unit root test allowing for a break in the intercept, it rejected the null of unit root at the 10 percent level of significance for the EPRR. This test identified a break for the series at 1987:Q4. In addition, the Lee and Strazicich(2003) unit root test allowing for 2 breaks, also rejected the null hypothesis of unit root test, with the breaks identified in 1972:Q3 and 1999:Q3.
} 
Fig. 2: Ex Post Real Interest Rate and Regime Specific Means, 1960:Q2-2010:Q4

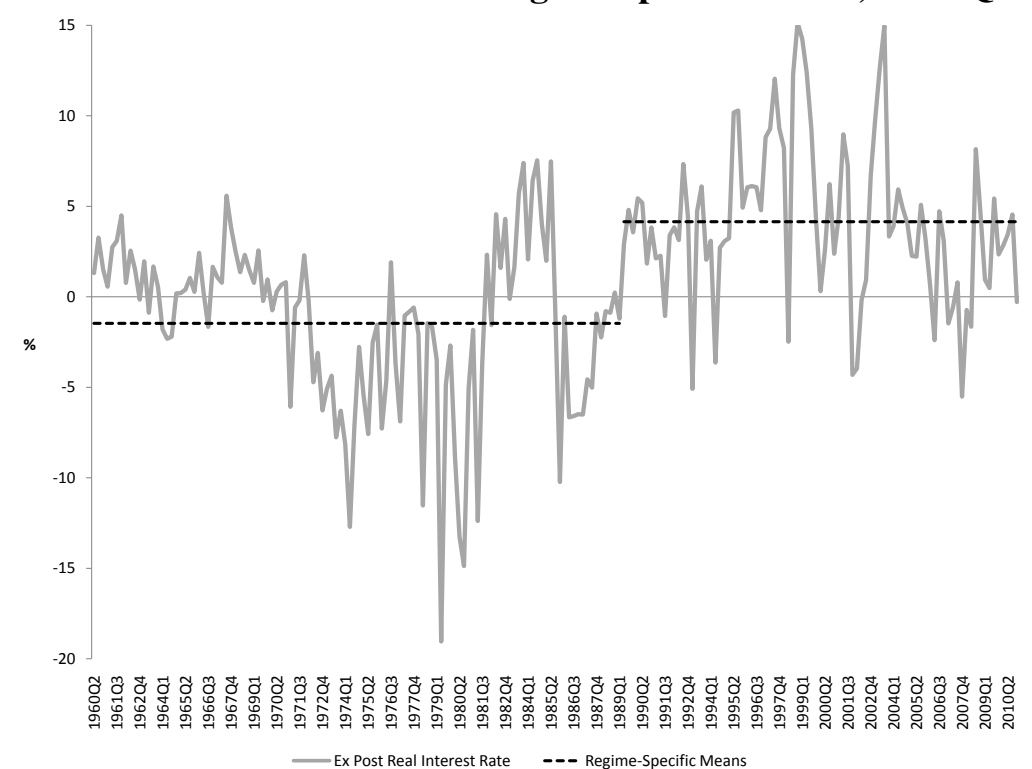

NOTE: Based on the Bai and Perron (1998) methodology, the figure plots the SA Ex post real interest rate and means for the regimes defined by the structural breaks.

for the mismatch in persistence. So now, we consider fiscal, monetary, and transient technology shocks as potential causes of persistent fluctuations in the real interest rate.

Figures 1 and 2 and the Bai and Perron (1998) structural break tests reveal a sharp increase in the real rate since 1989:Q2. The South African government did not undertake the sort of expansionary fiscal policy that would be necessary for such a rise in real rates. In fact, the budget deficits have been consistently declining over this period (until the "Great Recession" recently), as deduced from the data on budget deficit as a percentage of Gross Domestic Product published by the South African Reserve Bank. In fact, the average deficits over 1960:Q2-1989:Q1 and 1989:Q2-2010:Q4 have been virtually the same. Hence, fiscal shocks cannot be really viewed as a plausible candidate for the increase in real rates during this period. Turning to technology shocks, the lack of independent data on technology shocks makes it difficult to relate such changes with real interest rates. Besides, technology growth has been traditionally viewed as reasonably stable. Having said that, using a structural vector autoregressive framework to estimate the long-run effects of exogenous changes in the inflation rate on output and the real interest rate, Amusa et al., (forthcoming) indicate that persistence in real interest rate could be explained to some extent by technology shocks. Further, one could suggest that oil price increases, might influence the real rate, as can be seen from the negative real interest rate that prevailed over the decade of 1970 . However, it is less likely for oil price shocks alone to account for the pronounced swings in the South African real interest rate. This leaves us with the monetary policy shocks as an explanation for the persistence of EPRR.

When one delves into the history of monetary policy of South Africa, one realizes that the financial markets were regulated till the mid 1980, resulting in low nominal rates. Coupled with high rates of inflation, the negative real rates over the decade of the 1970 was obvious. After, the financial markets got liberalized, the South African Reserve Bank started pursuing a contractionary monetary policy since the 1990s as part of an informal inflation targeting framework. ${ }^{18}$ So, the increase in the average EPRR seems natural post 1989. While we interpret the timing of the

\footnotetext{
${ }^{18}$ Refer to Ludi and Ground (2006) for a detail discussion of the history of monetary policy in South Africa.
} 
Table 4: Bai and Perron (1988) Test Statistics and Estimation Results for Inflation Rate (1960:Q2-2010:Q4)

\begin{tabular}{llcc}
\hline \hline Test statistic & Regime & $\begin{array}{c}\text { Estimated } \\
\text { inflation rate mean }\end{array}$ \\
\hline$U D_{\max }$ & $113.64 * * *$ & $1960: \mathrm{Q} 2-1971: \mathrm{Q} 1[1970: \mathrm{Q} 2-1971: \mathrm{Q} 2]$ & $2.79 * * *(0.55)$ \\
$W D_{\max }(5 \%)$ & $163.60^{* * *}$ & $1971: \mathrm{Q} 2-1993: \mathrm{Q} 2[1990: \mathrm{Q} 3-1994: \mathrm{Q} 4]$ & $12.40^{* * *}(0.39)$ \\
$F(1 \mid 0)$ & $64.78^{* * *}$ & $1993: \mathrm{Q} 3-2010: \mathrm{Q} 4$ & $6.23 * * *(0.43)$ \\
$F(2 \mid 1)$ & $36.88^{* * *}$ & & \\
$F(3 \mid 2)$ & 8.75 & & \\
$F(4 \mid 3)$ & 2.14 & & \\
$F(5 \mid 4)$ & 0 & & \\
\hline \hline
\end{tabular}

NOTE: *,**,*** indicate significance at the $10 \%, 5 \%, 1 \%$ levels. The bracketed dates in the Regime column denote a $90 \%$ confidence interval for the end of the regime. Numbers in parentheses in the last column denote standard errors for the estimated mean.

Fig. 3: Inflation Rate and Regime Specific Means, 1960:Q2-2010:Q4

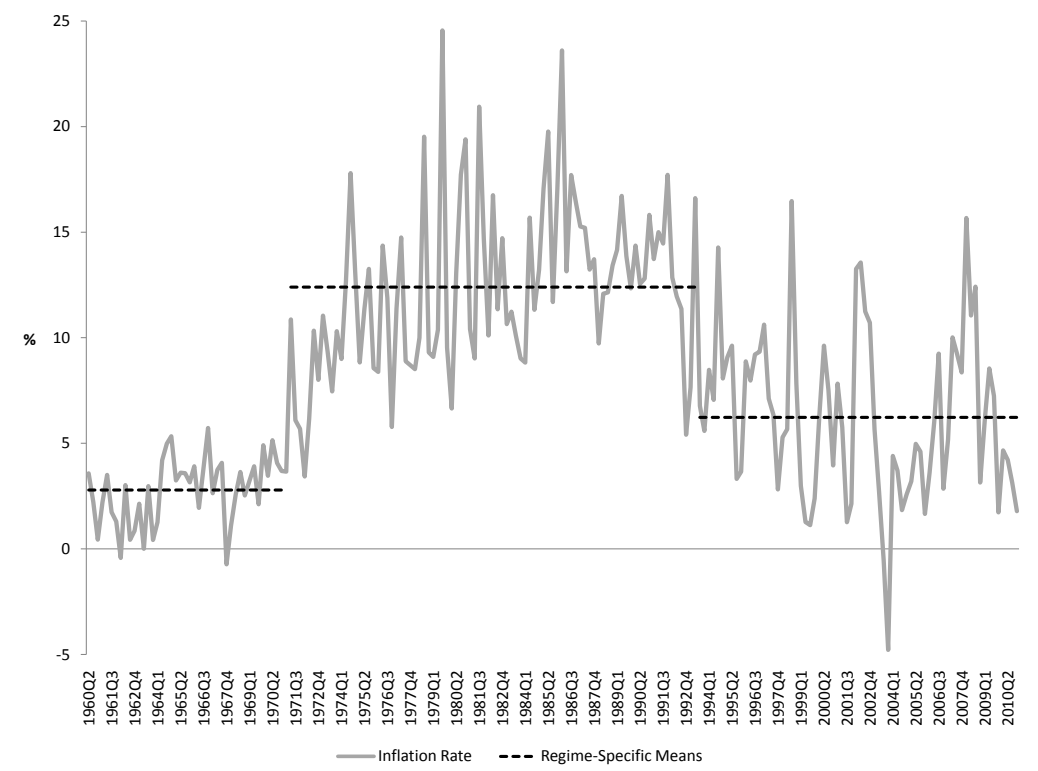

NOTE: Based on the Bai and Perron (1998) methodology, the figure plots the SA inflation rate and means for the regimes defined by the structural breaks.

major swing in the real rate to suggest a monetary explanation, we ultimately need to provide formal evidence for this line of reasoning. Hence, following Rapach and Wohar (2005), we use the Bai and Perron (1998) methodology to try and explain the deterministic regime shifts in the EPRR by considering regime shifts in the mean inflation rate. According to Friedman (1963), changes in the mean inflation rate can be considered to be a monetary phenomenon. Table 4 reports the results of the Bai and Perron (1998) methodology for the inflation rate. Two significant changes in the mean of inflation rate are identified to occur in 1971:Q1 and in 1993:Q2. For the period between 1960:Q2 and 1971:Q1, the average inflation rate was at 2.79 percent; for the period between 1971:Q2 and 1993:Q2 it averaged at 12.40 percent and for the period between 1993:Q3 and 2010:Q4, the average mean decreased to 6.23 percent. Figure 3 plots the South African inflation rate and the means for the regimes defined by the structural breaks estimated. In general, it can be seen that periods of low inflation are associated with periods of high rates of the EPRR. However, the break in the inflation rate in 1990:Q3 is about four years later than the only identified break in the real interest rate. Though, it must be said that the lower limit of the 90 
percent confidence band for the structural break of the inflation rate falls within the corresponding 90 percent confidence interval of the EPRR. Thus, the evidence that a regime shift in the mean inflation rate tend to correspond to the regime shift in the mean real interest rate is weak. ${ }^{19}$

\section{Bayesian Change Point Analysis}

Given the weak evidence that the EPRR persistence is a monetary phenomenon based on the structural break test, we decided to look into this issue further using a Bayesian change point analysis for the real rate and the inflation rate. This method allows us to obtain posterior probabilities of a change for each point of the two series, thus, (possibly) allowing us to better relate inflation with the persistence of the EPRR. In the following paragraphs, we describe the Barry and Hartigan (1993) algorithm for the Bayesian change point methodology.

The Barry and Hartigan (1993) algorithm models the series generating process by assuming that there is an underlying sequence of parameters partitioned into contiguous blocks of equal parameter values. The beginning of each block is then a change point, while observations are assumed to be independent in different blocks given the sequence of parameter. Let $X_{1}, X_{2}, \ldots, X_{n}$ be independent observations, with each $X_{i}$ having a density dependent on $\theta_{i}, i=1, \ldots, n$. Furthermore, there exists an unknown number of contiguous blocks with partitions $\rho=\left\{i_{0}, i_{1}, \ldots, i_{b}\right\}$ such that $0=i_{0}<i_{1}<\ldots<i_{n}=n$ and $\theta_{i}=\theta_{i_{b}}$ when $i_{r-1}<i \leq i_{r}$.

In the notation used by Barry and Hartigan (1993), let $X_{i j}$ denote the sequence of points $X_{i+1}, \ldots, X_{j}$ in time. Let $f_{i j}\left(x_{i j} \mid \theta_{j}\right)$ denote the density of $x_{i j}$ when $\theta_{i+1}=\theta_{i+2}=\ldots=\theta_{j}$. For constant blocks, a transition distribution is defined as follows: Given $\theta_{i}, \theta_{i+1}$ equals $\theta_{i}$ with probability $1-p_{i}$ or has density $f\left(\theta_{i+1} \mid \theta_{i}\right)$ with probability $p_{i}$. This in essence implies that smaller values of $p_{i}$ will result in longer $\theta_{i}$ blocks.

Further, the probability of a partition $\rho=i_{0}, i_{1}, \ldots, i_{b}$ is given by $f(\rho)=K c_{i_{0} i_{i}} c_{i_{1} i_{2}} \ldots c_{i_{b-1}} i_{b}$ where $c_{i j}$ are prior cohesion for adjacent blocks $i j$. In notations, let $X_{1}, X_{2}, \ldots, X_{n}$ are assumed to be an independent for a given sequence of $\mu_{i}$, such that $X_{i} \sim N\left(\mu_{i}, \sigma^{2}\right), i=1,2, \ldots, n$. A prior cohesion $c_{i j}$ following Yao (1984) is introduced as follows:

$$
c_{i j}= \begin{cases}(1-p)^{j-i-1} p, & j<n \\ (1-p)^{j-i-1} & j=n\end{cases}
$$

Also, a block prior is introduced as follows:

$$
f_{i j}\left(\mu_{j}\right) \sim N\left(\mu_{0}, \frac{\sigma_{0}^{2}}{j-i}\right)
$$

\footnotetext{
${ }^{19}$ Using a measure of monetary policy surprise developed by Reid (2009) and Gupta and Reid (forthcoming), we analyzed the impulse response function of the EPRR obtained from an autoregressive distributed lag (ARDL) model following a contractionary monetary policy shock over the period of 2002:Q2-2010:Q4. The results, based on Romer and Romer's (2004) Monte Carlo methods to generate confidence bands for the impulse response functions, indicated a delayed very short-lived (1 quarter) positive effect on the EPRR, suggesting again a weak monetary explanation of the persistence of the real rate - a result in line with the findings of Amusa et al., (forthcoming). The impulse response functions from the ARDL model is available upon request from the authors. Note, Reid (2009) and and Gupta and Reid (forthcoming) used the change in the 3-months Banker's Acceptance rate on the day after the monetary policy committee makes its statement as a proxy for the surprise component of monetary policy. This event-based data was converted to a quarterly frequency by averaging the shocks over a three month period.
} 
The priors distribution for each of $\mu_{0}, \sigma_{0}^{2}, p, w=\frac{\sigma^{2}}{\left(\sigma_{0}^{2}+\sigma^{2}\right)}$ are as follows:

$$
\begin{aligned}
f\left(\mu_{0}\right) & =1,-\infty \leq \mu_{0} \leq \infty \\
f\left(\sigma^{2}\right) & =1 / \sigma^{2}, 0 \leq \sigma^{2} \leq \infty \\
f(p) & =1 / p_{0}, 0 \leq p \leq p_{0} \\
f(w) & =1 / w_{0}, 0 \leq w \leq w_{0}
\end{aligned}
$$

After experimenting with different values of $w_{0}$ and $p_{0}$, we initialize $\left(p_{0}, w_{0}\right)$ with $(0.002,0.2)$ to ensure that the change points in the two series matches major local and global events that took place over the period of 1960:Q2-2010:Q4. As can be seen from Figure 4, a major change point in the inflation rate in 1972:Q1 preceded a major change point in the EPRR in 1972:Q2. Also, a major change point in the EPRR in 1992:Q3 followed a change point in the inflation rate in 1989:Q1, and is followed by couple of major changes in the inflation rate in 19954:Q4 and 1995:Q1. The other major change points in inflation in 1981 and 1985, seems to be in line with the move to a flexible exchange rate regime and liberalization of the domestic financial markets. While, the changes in the inflation rate in 1995 and late 1999 corresponds closely to the creation of democratic South Africa and its move to an inflation targeting regime in $2000 .{ }^{20}$ Relative to the evidence provided by the Bai and Perron (1998) tests of structural breaks, the Bayesian change point analysis seems to provide a slightly more stronger evidence in favor of the real interest rate persistence being a monetary phenomenon. However, it is important to emphasize, that the evidence is suggestive and more research is, perhaps, required (based on structural identification) to determine the veracity of the monetary explanation for the persistence of the real interest rate of South Africa.

Fig. 4: Posterior Probabilities of Change for the Ex post Real Rate and the Inflation Rate

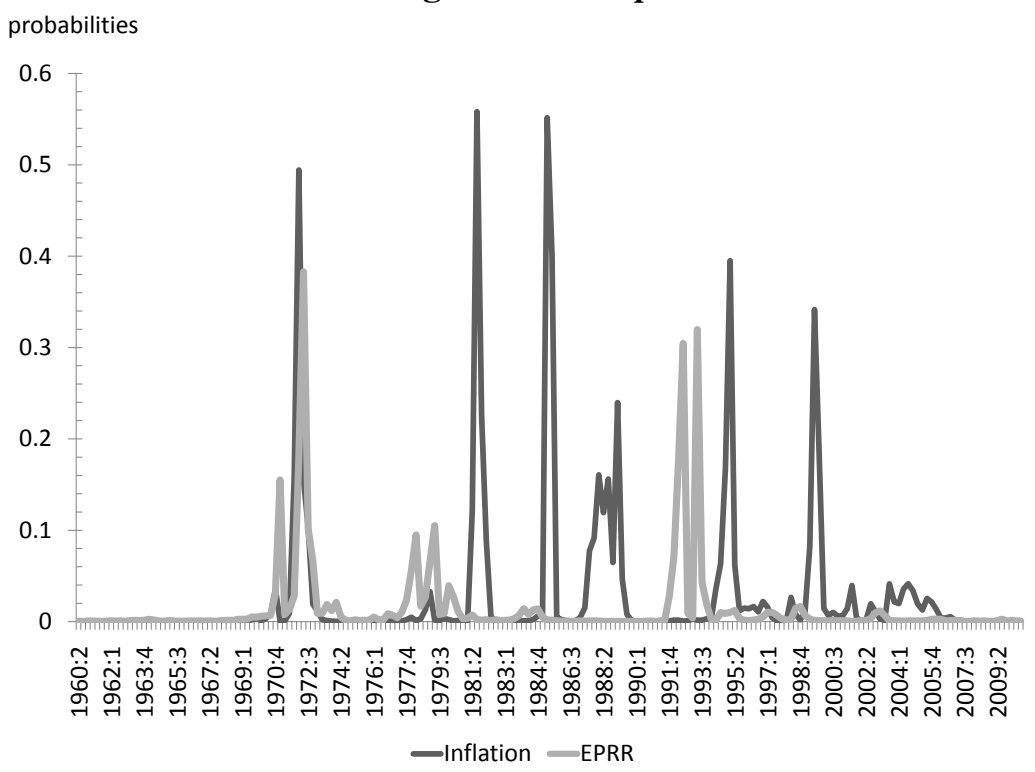

\section{Conclusion}

Rose's (1988) influential work stimulated a considerable empirical literature that investigates the time-series properties of real interest rates. Surprisingly, there does not exist any study that delves

\footnotetext{
${ }^{20}$ We used the bcp package in R, developed by Erdman and Emerson (2007), to implement the algorithm of Barry and Hartigan (1993).
} 
into this issue for South Africa. Against this backdrop, using quarterly data (1960:Q2-2010:Q4) for South Africa, our paper endeavors to analyze the long-run properties of the ex post real rate (EPRR) using tests of unit root, cointegration, fractional integration, estimated confidence intervals for the sum of the autoregressive coefficients and structural breaks. In addition, we also analyze whether monetary shocks contribute to fluctuations in the real interest rate based on the Bai and Perron (1998) test of structural breaks of the rate of inflation, as well as, Bayesian change point analysis proposed by Barry and Hartigan (1993). We find evidence that the 3-month Treasury bill rate based real interest rate seems stationary, with estimated 95 percent confidence intervals for the sum of the AR coefficients having an upper bound that is very close to unity. Further, the EPRR appear to display long-memory behavior; implying effects of shocks being very long-lived, but the real interest rate is estimated to be ultimately mean-reverting. In addition, structural breaks in unconditional means characterize the EPRR. Although the breaks reduce within-regime persistence, the real interest rate remains highly persistent because the regimes have different means. Further, we observed that, real interest is far more persistent than the consumption growth rate, thus raising doubts about the validity of the consumption-based asset pricing models. Complex equilibrium growth models tend to potentially explain this persistence mismatch through changing fiscal and monetary policy, as well as temporary technology growth shocks. Our results based on test of structural breaks of the rate of inflation, and in particular, Bayesian change point analysis, tentatively concludes that the mismatch in the persistence of the real interest rate and consumption growth rate is more likely to be a monetary phenomenon than a outcome of fiscal policy and transient technology growth shocks. In the future, further analysis of the relative importance of different types of shocks in explaining real interest rate persistence could be of immense help to this literature.

Note that, from a policy perspective, there is a tremendous need to determine whether the process of real interest rate is stationary or not, since it determines the frequency at which the central bank would need to intervene into the markets. This information is of paramount importance for South Africa specifically, given that it has moved to an inflation-targeting regime since the first quarter of 2000.The success of an inflation-targeting regime is dependant on keeping the inflation expectations pegged, which in turn, depends on clear communication to the market, and hinges crucially to a great extent on whether the real interest rate is stationary or not. Since if the real interest rate is believed to have an unit root process, the South African Reserve Bank might have to intervene regularly to neutralize the possibility of a permanent effect on the market; in the process confusing agents and their inflation expectations, and thus leading the inflation to deviate away from the target. In light of this, it seems that it is better to err on the side of stationarity, even when the interest rate process might be an unit root, since if the South African Reserve Bank observes that their policies are actually having permanent effect when they want it to be temporary, they could always intervene as required. However, if the real interest rate is actually mean-reverting, but the South African Reserve Bank believes it to be an unit root process, they are likely to end up frequently intervening in the market, when they do not actually need to, and thus making it difficult for agents to appropriately form their expectations.

\section{References}

Andolfatto, D., Hendry, S. and Moran, K. "Are Inflation Expectations Rational?" Journal of Monetary Economics, 2008, 55(2), pp. 406-22.

Amusa, K., Gupta, R., Karolia, S. and Simo-Kengne, B. D. "The Long-Run Impact of Inflation in South Africa." Journal of Policy Modeling, Forthcoming. 
Bai, J. and Perron, P. "Estimating and Testing Linear Models with Multiple Structural Changes.” Econometrica, 1998, 66(1), pp. 47-78.

Barro, R. J. and Sala-i-Martin, X. "Economic Growth.” Second Edition. Cambridge, MA: MIT Press, 2003.

Barry, D. and Hartigan J. A. "A Bayesian Analysis for Change Point Problems." Journal of the American Statistical Association, 1993, 88, pp. 309-19.

Baxter, M. and King, R. G. "Fiscal Policy in General Equilibrium." American Economic Review, 1993, 83(3), pp. 315-34.

Bierens, H. J. "Nonparametric Nonlinear Cotrending Analysis, with an Application to Interest and Inflation in the United States." Journal of Business and Economic Statistics, 2000, 18(3), pp. 323-37.

Bierens, H. J. "Nonparametric Nonlinear Co-Trending Analysis, with an Application to Interest and Inflation in the U.S." Journal of Business and Economic Statistics, 2000, 18, pp. 323-37.

Blanchard, O. J. "Debt, Deficits, and Finite Horizons.” Journal of Political Economy, 1985, 93(2), pp. 223-47.

Blanchard, O. J. and Fischer, S. Lectures on Macroeconomics. Cambridge, MA: MIT Press, 1989.

Blough, S. R. "The Relationship Between Power and Level for Generic Unit Root Tests in Finite Samples." Journal of Applied Econometrics, 1992, 7(3), pp. 295-308.

Breeden, D. T. "An Intertemporal Asset Pricing Model with Stochastic Consumption and Investment Opportunities.” Journal of Financial Economics, 1979, 7(3), pp. 265-96.

Breitung, J. "Nonparametric Tests for Unit Roots and Cointegration." Journal of Econometrics, 2002, 108(2), pp. 343-63.

Bullard, J. B. and Russell, S. H. "How Costly Is Sustained Low Inflation for the U.S. Economy?” Federal Reserve Bank of St. Louis Review, May/June 2004, 86(3), pp. 35-67.

Cass, D. "Optimum Growth in an Aggregate Model of Capital Accumulation." Review of Economic Studies, 1965, 32(3), pp. 233-40.

Crowder, W. J. and Wohar, M. E. "Are Tax Effects Important in the Long-Run Fisher Relation? Evidence From the Municipal Bond Market." Journal of Finance, 1998, 54(1), pp.307317.

Darby, M. R. "The Financial and Tax Effects of Monetary Policy on Interest Rates." Economic Inquiry, 1975, 13(2), pp. 266-76.

de Bruyn, R., Gupta, R. and Stander, L. "Testing the Monetary Model for Exchange Rate Determination in South Africa: Evidence from 101 Years of Data." Contemporary Economics, Forthcoming.

DeJong, D. N., Nankervis, J. C., Savin, N. E. and Whiteman, C. H. "The Power Problems of Unit Root Tests in Time Series with Autoregressive Errors." Journal of Econometrics, 1992, 53(1-3), pp. 323-43. 
Diamond, P. A. "National Debt in a Neoclassical Growth Model." American Economic Review, 1965, 55(5), pp. 1126-50.

Dickey, D. A. and Fuller, W. A. "Distribution of the Estimators for Autoregressive Time Series with a Unit Root." Journal of the American Statistical Association, 1979, 74(366), pp. 427-31.

Elliott, G., Rothenberg, T. J. and Stock, J. H. "Efficient Tests for an Autoregressive Unit Root." Econometrica, 1996, 64(4), pp. 813-36.

Engle, R. F. and Granger, C. W. J. "Co-integration and Error Correction: Representation, Estimation, and Testing." Econometrica, 1987, 55(2), pp. 251-76.

Erdman, C. and Emerson, J. W. "bcp; An R Package for Performing a Bayesian Analysis of Change Point Problems.” Journal of Statistical Software, 2007, 23(3), pp. 1-13.

Espinosa-Vega, M. A. and Russell, S. H. "Can Higher Inflation Reduce Real Interest Rates in the Long Run?" Canadian Journal of Economics, 1998a, 31(1), pp. 92-103.

Espinosa-Vega, M. A. and Russell, S. H. "The Long-Run Real Effects of Monetary Policy: Keynesian Predictions from a Neoclassical Model.' Federal Reserve Bank of Atlanta, 1998b, Working Paper No. 98-6.

Faust, J. "Near Observational Equivalence and Theoretical Size Problems with Unit Root Tests." Econometric Theory, 1996, 12(4), pp. 724-31.

Fisher, I. "The Theory of Interest.” MacMillan: New York, 1930.

Geweke and Porter-Hudak. "The Estimation and Application of Long Memory Time Series Models." Journal of Time Series Analysis, 1983, pp. 221-238.

Granger, C. W. J. "Long Memory Relationships and the Aggregation of Dynamic Models." Journal of Econometrics, 1980, 14(2), pp. 227-38.

Granger, C. W. J. and Joyeux, R. "An Introduction to Long-Memory Time Series Models and Fractional Differencing." Journal of Time Series Analysis, 1980, 1, pp. 15-39.

Gregory, A. W. and Hansen, B. E. "Residual-based tests for Cointegration in Models with Regime Shifts." Journal of Econometrics, 1996, 70(1), pp. 99-126.

Gupta, R. and Reid, M. "Macroeconomic Surprises and Stock Returns in South Africa." Studies in Economics and Finance, forthcoming.

Hamilton, J. D. "A New Approach to the Economic Analysis of Nonstationary Time Series and the Business Cycle.” Econometrica, 1989, 57(2), pp. 357-84.

Hansen, B. E. "The Grid Bootstrap and the Autoregressive Model." Review of Economics and Statistics, 1999, 81(4), pp. 594-607.

Hansen, L. P. and Singleton, K. J. "Generalized Instrumental Variables Estimation of Nonlinear Rational Expectations Models.” Econometrica, 1982, 50(5), pp. 1269-86.

Hansen, L. P. and Singleton, K. J. "Stochastic Consumption, Risk Aversion, and the Temporal Behavior of Asset Returns." Journal of Political Economy, 1983, 91(2), pp. 249-65.

Hosking, J. R. M. “Fractional Differencing.” Biometrika, 1981, 68(1), pp. 165-76. 
Huizinga, J. and Mishkin, F. S. "Monetary Policy Regime Shifts and the Unusual Behavior of Real Interest Rates." Carnegie-Rochester Conference Series on Public Policy, 1986, 24, pp. 231-74.

Johansen, S. "Estimation and Hypothesis Testing of Cointegration Vectors in Gaussian Vector Autoregressive Model.” Econometrica, 1991, 59(6), pp. 1551-80.

Jouini, J. and Nouira, L. "Mean-Shifts and Long-Memory in the U.S. Ex Post Real Interest Rate." Universit de la Mditerrane, GREQAM, 2006, Mimeo.

Kahn, B. and Farrell, G. "South African real Interest Rates in Comparative Perspective: Theory and Evidence." South African Reserve Bank Occasional Paper, 2002, No 17.

Kapetanios, G., Shin, Y. and Snell, A. "Testing for a Unit Root in the Non-Linear STAR Framework." Journal of Econometrics, 2003, 112, pp. 359-79.

Koopmans, T. C. "On the Concept of Optimal Economic Growth," in The Economic Approach to Development Planning. Amsterdam: Elsevier, 1965, pp. 225-300.

Kryshko, M. "Nominal Exchange Rates and Uncovered Interest Parity: Non-Parametric Cointegration Analysis." University of Pennsylvania Department of Economics, 2006, Mimeo.

Kwiatkowski, D., Phillips, P. C. B., Schmidt, P and Shin, Y. "Testing the Null Hypothesis of Stationarity Against the Alternative of a Unit Root: How Sure Are We That Economic Time Series Have a Unit Root?” Journal of Econometrics, 1992, 54(1-3), pp. 159-78.

Lacerda, M., Fedderke, J. W. and Haines, L. M. "Testing for Purchasing Power Parity and Uncovered Interest Parity in the Presence of Monetary and Exchange Rate Regime Shifts." The South African Journal of Economics, 2010, 78(4), pp. 363-382.

Lee, J. and Strazicich, C. M. "Minimum Lagrange Multiplier Unit Root Test with Two Structural Breaks." The Review of Economics and Statistics, 2003, 85(4), pp. 1082-89.

Li, J. and Lee, J. "Adl Tests for Threshold Cointegration.” Journal of Time Series Analysis, 2010, 31(4), pp. 241-54.

Lioui, A. and Poncet, P. "Monetary Non-Neutrality in the Sidrauski Model Under Uncertainty." Economics Letters, 2008, 100(1), pp. 22-26.

Lucas, R. E. “Asset Prices in an Exchange Economy.” Econometrica, 1978, 46(6), pp. 142945 .

Ludi, K. and Ground, M. "Investigating the Bank Lending Channel in South Africa: A VAR Approach." University of Pretoria Department of Economics Working Paper, 2006, No. 200604.

Lo. “Long-term Memory in Stock Market Prices”, Econometrica, 1991, 59, pp. 1279-1313.

Mishkin, F. S. "The Real Rate of Interest : An Empirical Investigation.” Carnegie-Rochester Conference Series on public policy, 1981, 15, pp. 151-200.

Mishkin, F. S. "The Real Interest :Rate : A Multi-Country Empirical Study." Canadian Journal of Economics, 1984, 17(2), pp. 283-311.

Mundell, R. "Inflation and Real Interest." Journal of Political Economy, 1963, 71(3) ,pp. 280-83. 
Neely C. J. and Rapach D. E. "Real Interest Rate Persistence: Evidence and Implications." Federal Reserve Bank of St. Louis Review, 2008, 90(6), pp.609-41.

Nelson, C. R. and Schwert, G. W. "Short-Term Interest Rates as Predictors of Inflation: On Testing the Hypothesis that the Real Interest Rate Is Constant." American Economic Review, 1997, 67(3), pp. 478-86.

$\mathrm{Ng}$, S. and Perron, P. "Lag Length Selection and the Construction of Unit Root Tests with Good Size and Power." Econometrica, 2001, 69(6), pp. 1519-54.

Peláez, R. F. “The Fisher Effect: Reprise.” Journal of Macroeconomics, 1995, 17(2), pp. $333-46$.

Perron, P. "The Great Crash, the Oil Price Shock and the Unit Root Hypothesis." Econometrica, 1989, 57(6), pp. 1361-401.

Perron, P. and Rodriguez, G. H. "Residual Based Tests for Cointegration with GLS Detrended Data." Boston University, 2001, Mimeo.

Phillips, P. C. B. and Perron, P. "Testing for a Unit Root in Time Series Regression." Biometrika, 1988, 75(2), pp. 335-46.

Rapach, D. E. and Wohar, M. E. "The Persistence in International Real Interest Rates." International Journal of Finance and Economics, 2004, 9(4), pp. 339-346.

Rapach, D. E. and Wohar, M. E. "Regime Changes in International Real Interest Rates: Are They a Monetary Phenomenon?" Journal of Money, Credit, and Banking, 2005, 37(5), pp. 887-906.

Reid, M. "The Sensitivity of South African Inflation Expectations To Surprises." South African Journal of Economics, 2009, 77(3), pp 414-29.

Reis, R. "The Analytics of Monetary Non-Neutrality in the Sidrauski Model." Economics Letters, 2007, 94(1), pp. 129-35.

Robinson, P.M. "Semi-parametric Analysis of Long-memory Time Series." Annals of Statistics, 1992, 22, pp. 515-39.

Romano, J. P. and Wolf, M. 2001."Subsampling Intervals in Autoregressive Models with Linear Time Trends.” Econometrica, 2001, 69(5), pp. 1283-314.

Romer, D. H. Advanced Macroeconomics. Third Edition. New York: McGraw-Hill, 2006.

Romer, C. D. and Romer, D. H. "A New Measure of Monetary Shocks: Derivation and Implications.” American Economic Review, 2004, 94(4), pp. 1055-84.

Rose, A. K. “Is the Real Interest Rate Stable?” Journal of Finance, 1988, 43(5), pp. 10951112 .

Samuelson, P. A. "An Exact Consumption-Loan Model of Interest with or without the Social Contrivance of Money." Journal of Political Economy, 1958, 66(6), pp. 467-82.

Shiller, R. J. "The Volatility of Long-Term Interest Rates and Expectations Models of the Term Structure.” Journal of Political Economy, 1979, 87(6), pp. 1190-1219. 
Shimotsu, K. "Exact Local Whittle Estimation of Fractional Integration with an Unknown Mean and Time Trend.” Queen's University Working Paper, 2008.

Sims, C. "Bayesian Skeptism on Unit Root Econometrics." Institute for Empirical Macroeconomics, 1988, University of Minnesota.

Taylor, J. B. "Discretion versus Policy Rules in Practice." Carnegie-Rochester Conference Series on Public Policy, 1993, 39, pp. 195-214.

Tobin, J. “Money and Economic Growth.” Econometrica, 1965, 33(4), pp. 671-84.

Weiss, L. M. "The Effects of Money Supply on Economic Welfare in the Steady State." Econometrica, 1980, 48(3), pp. 565-76.

Yao, Y. "Estimation of a Noisy Discrete-Time Step Function: Bayes and Empirical Bayes Approaches." The Annal of Statistics, 1984, 12(4), pp. 1434-47.

Zivot, E. and Andrews, W. "Further Evidence on the Great Crash, the Oil Price Shock and the Unit Root Hypothesis." Journal of Business and Economic Statistics, 1992, 10, pp. 25170. 